\title{
DESEMPENHO E CARACTERÍSTICAS CONSTRUTIVAS DE UM PROTÓTIPO DE DOSADOR PNEUMÁTICO PARA SEMENTES DE ARROZ ${ }^{1}$
}

\author{
ÂNGELO V. DOS REIS ${ }^{2}$, FERNANDO A. FORCELLINI ${ }^{3}$
}

RESUMO: Tendo em vista a elevação do custo das sementes miúdas e a inadequação das semeadoras de precisão atuais, que não semeiam culturas com pequenos espaçamentos entre linhas, o presente trabalho teve o objetivo de apresentar os resultados dos testes de um protótipo de dosador pneumático, tipo cilindro vertical, para sementes de arroz. Foram avaliadas em laboratório a precisão na captação de sementes (com pressões de -56,0; -62,7 e $-73,1 \mathrm{kPa}$, velocidades tangenciais de 0,$10 ; 0,22$ e $0,30 \mathrm{~m} \mathrm{~s}^{-1}$, e orifícios dosadores de 1,2 e $1,5 \mathrm{~mm}$ ), a regularidade de distribuição longitudinal de sementes (com o reservatório de sementes com 25 e $50 \%$ da capacidade, inclinação lateral de 0 e $11^{\circ}$, orifícios com $1,5 \mathrm{~mm}$ ) e o dano mecânico de sementes, em experimentos inteiramente casualizados. As médias dos tratamentos foram comparadas por meio de análise de variância. Concluiu-se que os melhores resultados na captura foram obtidos na menor velocidade e com o menor nível de pressão, independentemente do tamanho do orifício. A percentagem de capturas simples chegou, em média, a 68,4\%, com orifício de $1,5 \mathrm{~mm}$. A precisão de dosagem alcançada na saída do tubo condutor foi de 37,6\% de tempos de aceitáveis. O nível de sementes no reservatório e a inclinação lateral não afetaram de forma significativa a precisão. $\mathrm{O}$ protótipo não aumentou significativamente o dano mecânico das sementes.

PALAVRAS-CHAVE: dosador de precisão, dosagem a vácuo, sementes miúdas.

\section{PERFORMANCE AND CONSTRUCTIVE CHARACTERISTICS OF A PNEUMATIC METER PROTOTYPE FOR RICE SEEDS}

\begin{abstract}
The increasing cost of seeds for the small grain crops and the inadequacy of the current precision planters, which do not sow crops with small inter roll spacing, this study has the objective of presenting the test results of a prototype vertical drum pneumatic meter for rice seeds. Laboratory tests were conducted to determine the seed metering precision (with pressure range of -56.0 ; -62.7 and $-73.1 \mathrm{kPa}$, peripheral speeds of $0.10,0.22$ and $0.30 \mathrm{~m} \mathrm{~s}^{-1}$, and hole diameters of 1.2 and $1.5 \mathrm{~mm}$ ), seed longitudinal distribution (with seed hoper at 25 and $50 \%$ of capacity, lateral inclination of 0 and $11^{\circ}$, and $1.5 \mathrm{~mm}$ diameter holes) and mechanical seed injury, in fully randomized experiments. Means of treatments were compared using analysis of variance. The conclusions were that the best results for seed meter were obtained with the lower speed with the lower pressure level, regardless of the hole size. The percentage of singles metering was as high as $68.4 \%$, in average, with the $1.5 \mathrm{~mm}$ diameter hole. The seed longitudinal distribution achieved $37.6 \%$ of singles times at the end of the seed tube. The level of seeds in hoper and the lateral inclination did not significantly affect the precision. The prototype did not raise the amount of injured seeds.
\end{abstract}

KEYWORDS: precision meters, vacuum metering, small seeds.

\footnotetext{
${ }^{1}$ Extraído da tese de Doutorado do primeiro autor.

${ }^{2}$ Eng $^{\mathbf{0}}$ Agrícola, Prof. Doutor, Departamento de Engenharia Agrícola, UFPel, Pelotas - RS, Fone: (0XX53) 3275.7126, areis@ufpel.tche.br

${ }^{3}$ Eng $^{\circ}$ Mecânico, Prof. Doutor, Departamento de Engenharia de Produção e Sistemas, UFSC, Florianópolis - SC, Fone: (0XX48)37217041, forcellini@ deps.ufsc.br

Recebido pelo Conselho Editorial em: 22-11-2007

Aprovado pelo Conselho Editorial em: 7-7-2009
} 


\section{INTRODUÇÃO}

A elevação do custo das sementes, motivada pela seleção de cultivares com maior potencial produtivo e pela adoção de outras tecnologias, como sementes híbridas e a transgenia, torna necessário o desenvolvimento de semeadoras que tenham controle mais efetivo sobre a população de plantas, o que pode ser conseguido com a utilização de semeadoras de precisão. Essas máquinas, comumente empregadas na semeadura de milho, por exemplo, possuem mecanismos dosadores que permitem a colocação de sementes espaçadas umas das outras, dentro da linha de semeadura, com distâncias previamente definidas, gerando, assim, potencial para a redução da quantidade de sementes utilizadas por hectare. Essa vantagem leva em conta a semeadura de sementes miúdas (arroz, trigo, cevada, aveia, centeio), que é feita, tradicionalmente, por semeadoras de fluxo contínuo, nas quais as sementes são distribuídas de forma continuada, não havendo separação definida das sementes dentro da linha de semeadura.

Uma análise do mercado de semeadoras feita por REIS \& FORCELLINI (2002) evidencia a ausência de semeadoras, tanto de fluxo contínuo como de precisão, capazes de trabalhar com baixas razões de distribuição de sementes miúdas. Segundo os autores, no caso das semeadoras de precisão, isso se deve tanto à dificuldade de individualizar e de transportar sementes de tamanho reduzido e de formas irregulares, quanto ao fato de essas culturas serem semeadas com pequenos espaçamentos entre linhas, requerendo mecanismos dosadores pequenos e estreitos, características essas, ausentes nos mecanismos dosadores de precisão atualmente empregados. A maioria dos dosadores de precisão não permite o emprego de distâncias entre linhas inferiores a $0,35 \mathrm{~m}$ (REIS, 2003).

Ao longo dos últimos dez anos, foram desenvolvidos experimentalmente alguns mecanismos dosadores de precisão para culturas de sementes miúdas. Em um deles, BUTIERRES (2003) utilizou mecanismo dosador de disco vertical a vácuo comercialmente disponível para a dosagem de sementes de arroz. Segundo o autor, os resultados foram satisfatórios (densidade de semeadura de 73 sementes por metro para a meta de 64) com discos de 36 orifícios de 1,6 mm de diâmetro. No entanto, não é explicado como esse dosador poderá ser empregado para semear culturas, como o arroz irrigado, que utilizam espaçamento entre linhas de $0,17 \mathrm{~m}$ (menor que a própria largura do dosador).

Segundo REIS (2003), o desempenho das semeadoras de precisão é afetado por quatro tipos de erros: dosagem, deposição, profundidade e acondicionamento. Os principais fatores que afetam os erros de dosagem são: características das sementes, relação de tamanho e de forma entre as células e as sementes, desempenho e desgaste de mecanismos auxiliares, e velocidade do componente rotativo. No que se refere à deposição das sementes, a precisão é afetada pela altura do dosador, configuração do tubo condutor, velocidade da semente e forma de deposição (natural ou forçada).

Especificamente para os dosadores pneumáticos, REIS et al. (2006) afirmam que há dois parâmetros de projeto particularmente importantes: o diâmetro do orifício pneumático e o diferencial de pressão empregado. Ambos estão diretamente ligados à velocidade e ao volume de ar que passa pelo orifício e, consequentemente, às forças que irão captar e transportar as sementes. Os autores concluíram, entre outras coisas, que o aumento do diâmetro do orifício de dosagem tem efeito mais pronunciado na captação das sementes do que redução na pressão e que houve aumento significativo no número de sementes captadas quando o diâmetro do orifício de dosagem passou de 1,5 para 2,0 mm, independentemente do diferencial de pressão empregado.

Tendo em vista, portanto, as limitações existentes para a semeadura de precisão de sementes miúdas, este artigo teve o objetivo de apresentar os resultados da avaliação funcional e mecânica de um protótipo de dosador pneumático tipo cilindro vertical, projetado conceitualmente para sementes miúdas de uma forma genérica, dimensionado e testado com sementes de arroz. $\mathrm{O}$ estudo procurou mostrar que é possível, pela minimização conjunta dos erros de dosagem e de deposição e pelo 
transporte forçado da semente entre o dosador e o solo, obter-se acuidade na distribuição longitudinal de sementes de arroz.

\section{MATERIAL E MÉTODOS}

\section{Descrição do dosador}

O mecanismo dosador de precisão para sementes de arroz desenvolvido ${ }^{4}$ e submetido aos ensaios é apresentado na Figura 1.

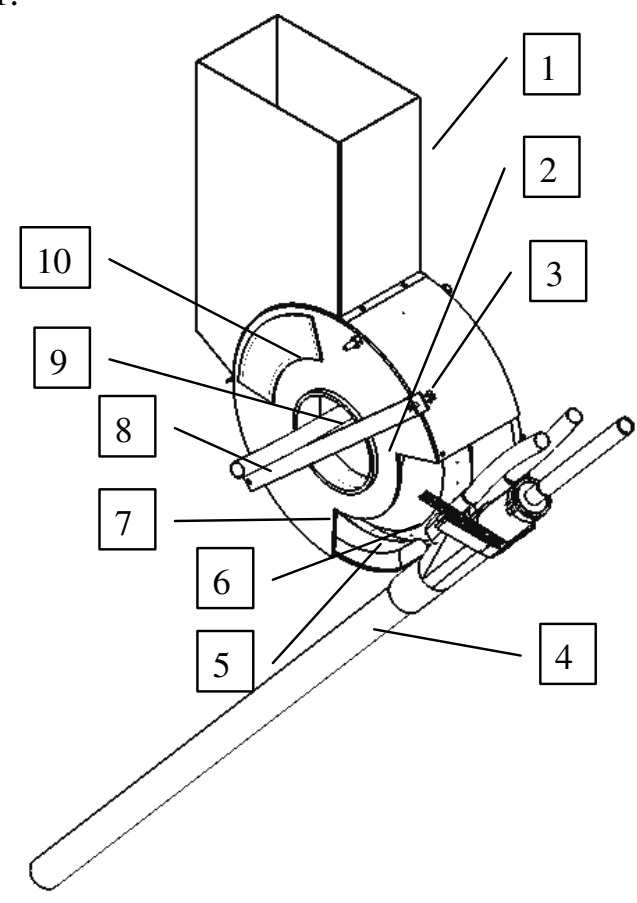

FIGURA 1. Vista em perspectiva do dosador pneumático tipo cilindro vertical, em que: (1) reservatório de sementes; (2) travessa de fixação; (3) carcaça; (4) tubo condutor com ejetores de sementes; (5) obturador de ar; (6) câmara de vácuo rotativa; (7) tampa lateral; (8) mangueira de ar (vácuo); (9) tampa estacionária pneumática; (10) visor. Perspective view of the vertical cylinder pneumatic meter, where: (1) seed hoper; (2) cross-setting; (3) housing; (4) seed tube with ejectors;(5) air valve; (6) a vacuum rotary chamber; (7) side cover; (8) air hose (vacuum); (9) stationary air cover; (10) display.

As sementes passam do reservatório (7 na Figura 2) pela ação da força da gravidade, até a região da câmara de dosagem, onde as sementes ficam expostas às fileiras de orifícios das duas faces operativas da câmara de vácuo rotativa (Figura 3), a qual gira no sentido horário - quando vista pelo lado da tampa lateral (7 na Figura 1). Os orifícios, $32 \mathrm{em}$ cada uma das faces operativas da câmara de vácuo, são desencontrados, de forma que a distância angular entre eles seja uniforme e constante. O diferencial de pressão entre a câmara de dosagem (pressão atmosférica) e a pressão no interior da câmara de vácuo rotativa (vácuo parcial) cria um fluxo de ar através dos orifícios que, por arrasto aerodinâmico, captura e prende uma semente em cada um dos orifícios. As sementes que não estiverem presas aos orifícios deslizam pelas faces operativas inclinadas da câmara de vácuo rotativa e retornam à câmara de dosagem. As sementes dosadas são transportadas até o local de ejeção, onde um par de ejetores pneumáticos (4 na Figura 2), um para cada fileira de orifícios, direcionam um jato de ar de baixa pressão e alta velocidade tangencialmente à trajetória das sementes, fazendo com que sejam desalojadas dos orifícios pneumáticos e direcionadas para o tubo condutor de sementes (4 na Figura 1) até o solo.

\footnotetext{
${ }^{4}$ Este protótipo é objeto do depósito n ${ }^{\circ}$ INPI SC 005487 junto ao Instituto Nacional de Propriedade Industrial em 17-12-2004.
} 


\section{Bancada de teste}

A fim de avaliar a precisão funcional das soluções desenvolvidas, foi necessário construir uma bancada de ensaio laboratorial de dosadores de sementes, a qual pode ser parcialmente vizualizada na Figura 2.

O dosador foi acionado por um motor de passo Warner Electric modelo KML092F07, que produz um torque máximo de 4,23 $\mathrm{N}$ m (que é multiplicado 4,8 vezes, chegando a $20,30 \mathrm{~N} \mathrm{~m}$, através de um conjunto de rodas dentadas e corrente, que transmite o movimento do motor ao eixo de acionamento do dosador), com variação de velocidade angular entre 0,23 e 62,5 rpm.

Para a contagem das sementes, utilizou-se de um sensor de fibras ópticas. A luz emitida através de um conjunto de fibras ópticas tem o seu nível comparado ao da entrada, através do módulo do sensor. O sinal digital gerado pelo módulo do sensor é então tratado num circuito eletrônico provido de um microcontrolador. $O$ tratamento do sinal permite que, mesmo que a semente não interrompa diretamente um dos 16 feixes de luz, os quais estão separados por uma distância de 3,8 mm, ela possa ser detectada pelo sistema. O sinal tratado no microcontrolador, via programa, é enviado para o computador através de uma porta de comunicação serial RS-232, para que o tempo entre a passagem de sementes consecutivas possa ser armazenado em arquivo. Outras informações podem ser obtidas de MARTINS et al. (2003).

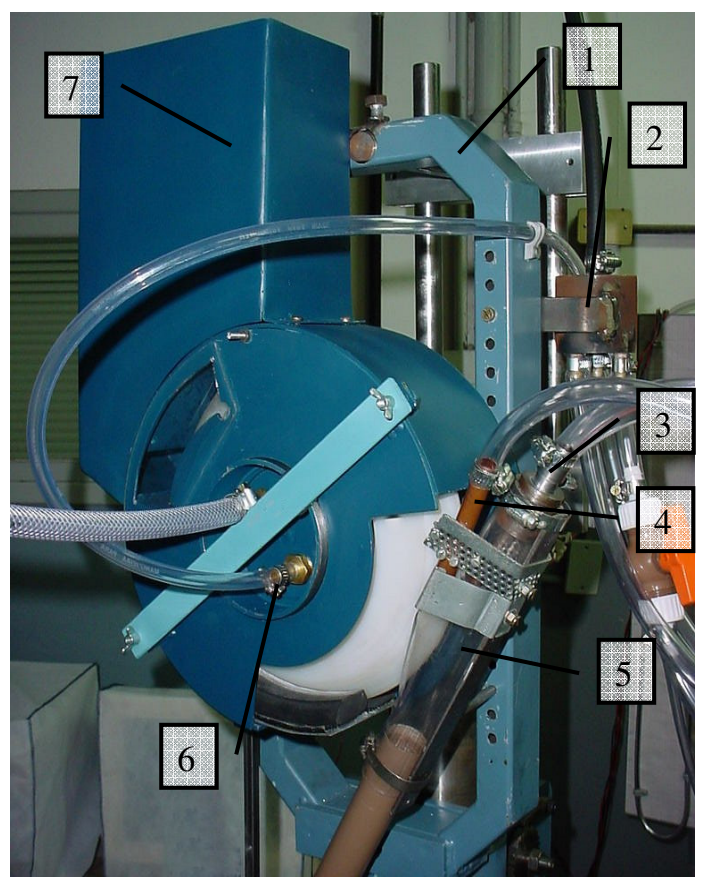

FIGURA 2. Protótipo montado na bancada de testes, em que: 1) mesa móvel de fixação; 2) válvula de distribuição de ar comprimido; 3) tomada de ar comprimido para transporte de sementes; 4) ejetores pneumáticos; 5) tubo flexível de recebimento de sementes; 6) tomada de ar para o manômetro; 7) reservatório de sementes. Prototype mounted on the test bench, where: 1) sliding table-setting; 2) compressed air distribution valve; 3) compressed air intake to carry seeds; 4) pneumatic ejectors; 5) flexible tube for receiving seeds; 6) air intake to gauge; 7) seed hoper.

Como fonte de vácuo, utilizou-se da linha de aspiração de um compressor de ar da marca Douat, modelo MLDW-420, de três cilindros, que fornece vazão máxima de $0,007 \mathrm{~m}^{3} \mathrm{~s}^{-1}$. Nessa configuração, a pressão negativa mínima obtida foi de $-90 \mathrm{kPa}$. Também foi utilizado um manômetro de coluna de mercúrio, com escala vertical graduada em milímetros, para a determinação das pressões de ar negativas envolvidas. 


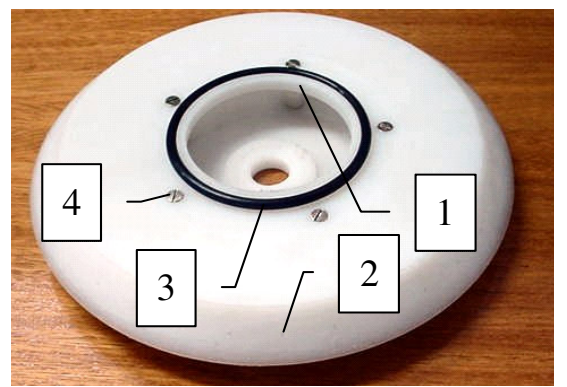

FIGURA 3. Aspecto externo da câmara de vácuo rotativa, em que: 1) sede do anel de vedação; 2) superfície dos orifícios de dosagem; 3) anel "O" de vedação; 4) parafuso de fixação. External view of the rotary vacuum chamber, where: 1) seat of the o-ring; 2) surface of the metering holes; 3) o-ring sealing; 4) fixing screw.

\section{Metodologia de avaliação}

A efetividade do dosador pneumático na dosagem de sementes de arroz foi verificada por meio de dois experimentos. No primeiro, foi avaliada a capacidade do dosador em captar e em transportar as sementes até o local de ejeção. Após, foi realizado um experimento para medir a distribuição longitudinal de sementes do dosador como um todo, com as medições feitas na saída do tubo condutor. Em ambos os casos, procurou-se seguir o que preconiza a ABNT (1994) para os ensaios de laboratório de semeadoras-adubadoras.

\section{Captação de sementes}

A efetividade do cilindro pneumático na captação (dosagem) de sementes foi avaliada contando-se o número de sementes presas em cada orifício de dosagem em diversas condições de operação. As variáveis independentes estudadas foram: velocidade tangencial dos orifícios, pressão manométrica do ar e diâmetro dos orifícios. A velocidade tangencial dos orifícios foi variada em três níveis $\left(0,10 ; 0,22\right.$ e $0,30 \mathrm{~m} \mathrm{~s}^{-1}$, correspondendo a rotações de 8,8;18,6 e 25,8 rpm, respectivamente). Devido à excessiva vibração induzida pelo motor de passo na bancada de teste na velocidade tangencial de $0,20 \mathrm{~m} \mathrm{~s}^{-1}$, esse valor teve de ser aumentado para $0,22 \mathrm{~m} \mathrm{~s}^{-1}$, caso contrário havia o desprendimento das sementes dosadas durante o transporte até o ponto de ejeção. O nível superior do fator velocidade $\left(0,30 \mathrm{~m} \mathrm{~s}^{-1}\right)$ foi a maior velocidade tangencial comumente recomendada para dosadores de sementes do tipo disco horizontal.

A pressão manométrica no interior da câmara de vácuo também foi variada em três níveis (56,0; -62,7 e -73,1 kPa). Esses valores tiveram por base estudos de REIS et al. (2006) com câmara de dosagem estacionária, correspondendo à pressão manométrica em fluxo bloqueado, isto é, as pressões obtidas com todos os orifícios do cilindro completamente bloqueados. No entanto, durante a execução dos testes, anotou-se a pressão manométrica no interior da câmara de vácuo. Dois diâmetros de orifícios foram testados: 1,2 e 1,5 mm (os valores escolhidos também foram baseados no estudo de REIS et al., 2006).

A variável de resposta principal desse experimento é a precisão na captura de sementes, expressa por meio da percentagem de capturas nulas, de capturas simples e de capturas múltiplas em relação ao número total de orifícios avaliados. Essa métrica é similar à percentagem de enchimento de células. No entanto, traz mais informações, pois diferencia o tipo de captura. As contagens foram feitas a partir de imagens gravadas da parte posterior do protótipo (foram retirados os ejetores de sementes e o tubo condutor) durante a execução de cada teste. Nos testes com velocidade tangencial de $0,10 \mathrm{~m} \mathrm{~s}^{-1}$, foi empregada uma câmara fotográfica digital (marca Sony, modelo MVC-FD100) com recursos de vídeo e resolução de 320 x 240 dpi. Nas outras velocidades, foi utilizada uma câmara de vídeo VHS de $8 \mathrm{~mm}$ (marca Sony, modelo FXD300BR) que, devido à possibilidade de utilizar o foco para objetos pequenos (macro), permitiu a gravação de imagens mais nítidas, facilitando a contagem das sementes. 
O delineamento experimental adotado para avaliar o efeito das variáveis apresentadas na precisão de captura de sementes foi o fatorial $3 \times 3 \times 2$, que gera 18 tratamentos, para os quais foram feitas quatro repetições com 250 orifícios cada. A ordem de execução dos tratamentos e repetições foi previamente sorteada.

As médias dos tratamentos foram comparadas por meio de análise de variância, acompanhada de um teste $\mathrm{T}$ para os casos em que houve interação entre os fatores.

Durante os testes, o nível de sementes no reservatório foi mantido em $50 \%$ da capacidade.

Foram utilizadas nos testes sementes básicas de arroz produzidas pela EMBRAPA/CPACT, da cultivar BRS 7, com $100 \%$ de pureza, umidade de $13 \%$ bu e $96 \%$ de germinação.

\section{Regularidade de distribuição longitudinal de sementes}

Noutro experimento, com novas sementes e outros fatores, procurou-se identificar os efeitos da variação do nível de sementes no reservatório e da variação da inclinação lateral do conjunto na regularidade de distribuição longitudinal de sementes. A inclinação lateral foi variada em dois níveis: $0^{\circ}$ (I0) e $11^{\circ}$ (I1). Esses valores são comumente utilizados nos ensaios de laboratório de mecanismos dosadores. O nível de sementes no reservatório foi variado, também, em dois níveis: $25 \%$ da capacidade (N1) e $50 \%$ da capacidade (N2).

O delineamento experimental adotado para avaliar o efeito das variáveis apresentadas na regularidade de distribuição longitudinal de sementes foi o fatorial $2 \times 2$, que gera quatro tratamentos, para os quais foram feitas seis repetições com 250 sementes cada. Da mesma forma que no experimento anterior, a ordem de execução dos ensaios foi previamente sorteada.

Para esse experimento, fixou-se a pressão em fluxo bloqueado em -73,1 kPa, a velocidade tangencial dos orifícios em $0,10 \mathrm{~m} \mathrm{~s}^{-1}(8,8 \mathrm{rpm})$, utilizando o diâmetro de $1,5 \mathrm{~mm}$. A pressão de ar de ejeção empregada nos testes foi de $200 \mathrm{kPa}$.

Os tempos-referência, medidos com o auxílio do sensor óptico de sementes junto à saída do tubo condutor, foram adotados como variável de resposta nesse experimento. Levando-se em consideração a rotação da câmara de vácuo e o número de orifícios, o tempo-referência (tempo entre passagem de orifícios consecutivos) é de 0,107 s. Então, de acordo com a ABNT (1994), os tempos falhos são aqueles maiores que $0,160 \mathrm{~s}$, os tempos aceitáveis ficam compreendidos entre 0,053 e $0,160 \mathrm{~s}$ e os tempos múltiplos são os menores que $0,053 \mathrm{~s}$.

As percentagens médias de tempos aceitáveis de cada tratamento foram comparadas por meio de análise de variância.

\section{Dano mecânico das sementes}

Foram recolhidas 13 amostras de 100 sementes na saída do tubo condutor, durante os testes da avaliação da precisão do protótipo, para a quantificação do dano mecânico causado às sementes. As determinações foram feitas por meio da contagem visual das sementes quebradas, descascadas e fissuradas presentes na amostra.

\section{Aspectos mecânicos e funcionais}

Além desses três ensaios, foram avaliados aspectos mecânicos e funcionais do protótipo, como: largura máxima, tempo de montagem e de desmontagem, e estanqueidade da câmara de vácuo rotativa.

O tempo necessário para a montagem e a desmontagem do protótipo fixado na bancada de testes foi cronometrado. Para a desmontagem do protótipo, é necessário o fechamento da comunicação do reservatório de sementes com a câmara de dosagem, a remoção da tampa pneumática com a soltura da travessa de fixação, a retirada da tampa lateral da câmara de dosagem, a retirada do conjunto do obturador e do próprio cilindro dosador pneumático. Para a montagem, segue-se a ordem inversa. 
Realizou-se teste de estanqueidade da câmara de vácuo, para verificar se havia entrada de ar entre o anel "o" e a tampa. Para tanto, os 64 orifícios de dosagem foram vedados com fita adesiva e aplicadas pressões de -3,0; -17,0; -31,0 e -73,1 kPa. Após a estabilização da pressão, o cilindro era acionado para verificar se havia vazamento de ar para o interior da câmara de vácuo, o que seria observado pelo aumento da pressão interna.

\section{RESULTADOS E DISCUSSÃO}

\section{Captação de sementes}

A análise estatística foi feita apenas sobre as médias das capturas simples, que é o parâmetro de maior interesse. Como a análise de variância mostrou que há interação estatisticamente significativa entre a pressão (p) e a velocidade tangencial (v) e também entre a pressão e o diâmetro dos orifícios (d), as percentagens médias de capturas simples de sementes, para esses dois casos de interação, são mostradas na Tabela 1. Na Figura 4, pode-se ver uma foto do experimento com as sementes presas aos orifícios.

A análise dos resultados estatísticos quanto à interação entre os efeitos da pressão e da velocidade ( $\mathrm{p}$ x v) sobre a percentagem de capturas simples revela que somente houve aumento da variável de reposta quando a pressão foi reduzida de $-62,7$ para $-73,1 \mathrm{kPa}$. No entanto, isso não foi válido para a maior velocidade tangencial, na qual não houve aumento significativo na percentagem de sementes capturadas com a redução na pressão, o que pode ser atribuído ao grande diferencial de velocidade entre as sementes na câmara de dosagem e os orifícios, e ainda ao menor tempo de exposição das sementes aos orifícios. Observa-se, também, redução no parâmetro de resposta à medida que a velocidade tangencial é aumentada em todos os níveis de pressão. Porém, na pressão de $-56,0 \mathrm{kPa}$, isso somente é observado quando a velocidade passa de 0,22 para $0,30 \mathrm{~m} \mathrm{~s}^{-1}$. Nas pressões de $-62,7$ e $-73,1 \mathrm{kPa}$, a redução já pode ser observada quando a velocidade é aumentada do primeiro para o segundo nível. À primeira vista, parece haver incoerência no fato de as capturas simples reduzirem-se menos nos maiores níveis de pressão, mas isso pode ser atribuído aos baixos valores obtidos com o orifício de maior diâmetro, devido à grande redução na pressão efetiva no interior da câmara de vácuo causada pela passagem do ar através dos orifícios sem sementes.

TABELA 1. Percentual médio de capturas de sementes pelo cilindro pneumático e comparação entre as médias das interações significativas (pressão $\mathrm{x}$ velocidade e pressão $\mathrm{x}$ diâmetro). Average percentage of seed catches by pneumatic cylinder and means comparision of the significant interactions (pressure $x$ speed and pressure $x$ diameter).

\begin{tabular}{|c|c|c|c|c|c|c|c|c|c|c|}
\hline \multirow{3}{*}{$\begin{array}{c}\text { Velocidade } \\
\text { Tangencial } \\
\left(\mathrm{m} \mathrm{s}^{-1}\right)\end{array}$} & \multirow{3}{*}{$\begin{array}{l}\text { Tipo de } \\
\text { captura }\end{array}$} & \multicolumn{9}{|c|}{ Pressões Manométricas de Fluxo Bloqueado (kPa) } \\
\hline & & \multicolumn{3}{|c|}{$-56,0$} & \multicolumn{3}{|c|}{$-62,7$} & \multicolumn{3}{|c|}{$-73,1$} \\
\hline & & $1,2 \mathrm{~mm}$ & $1,5 \mathrm{~mm}$ & $\begin{array}{c}\text { Médias } \\
\text { p X v }\end{array}$ & $1,2 \mathrm{~mm}$ & $1,5 \mathrm{~mm}$ & $\begin{array}{c}\text { Médias } \\
\text { p X v }\end{array}$ & $1,2 \mathrm{~mm}$ & $1,5 \mathrm{~mm}$ & $\begin{array}{c}\text { Médias } \\
\text { p X v }\end{array}$ \\
\hline \multirow{3}{*}{0,10} & Nula & 54,0 & 77,2 & \multirow{3}{*}{$32,7 \mathrm{bA}$} & 59,8 & 57,3 & \multirow{3}{*}{$39,3 \mathrm{bA}$} & 34,2 & 16,0 & \multirow{3}{*}{$64,9 \mathrm{aA}$} \\
\hline & Simples & 44,1 & 21,2 & & 39,5 & 39,0 & & 61,4 & 68,4 & \\
\hline & Múltipla & 1,9 & 6,4 & & 0,8 & 3,7 & & 4,4 & 15,6 & \\
\hline \multirow{3}{*}{0,22} & Nula & 56,4 & 94,9 & \multirow{3}{*}{$23,3 \mathrm{bA}$} & 69,5 & 90,2 & \multirow{3}{*}{$19,3 \mathrm{bB}$} & 55,3 & 66,9 & \multirow{3}{*}{$36,8 \mathrm{aB}$} \\
\hline & Simples & 41,4 & 5,2 & & 28,9 & 9,7 & & 41,8 & 31,8 & \\
\hline & Múltipla & 2,3 & 0,0 & & 1,6 & 0,1 & & 1,9 & 1,3 & \\
\hline \multirow{3}{*}{0,30} & Nula & 91,7 & 94,6 & \multirow{3}{*}{$6,7 \mathrm{aB}$} & 85,5 & 93,4 & & 85,8 & 86,2 & \multirow{3}{*}{$13,6 \mathrm{aC}$} \\
\hline & Simples & 7,9 & 5,4 & & 17,4 & 6,0 & $11,7 \mathrm{aB}$ & 13,9 & 13,2 & \\
\hline & Múltipla & 0,4 & 0,0 & & 0,1 & 0,1 & & 0,3 & 0,6 & \\
\hline Médias & $1,2 \mathrm{~mm}$ & $31,1 \mathrm{aA}$ & - & & $28,6 \mathrm{aA}$ & - & & $39,0 \mathrm{aA}$ & - & \\
\hline $\mathrm{p} \times \mathrm{d}$ & $1,5 \mathrm{~mm}$ & - & $10,6 \mathrm{bB}$ & & - & $18,2 \mathrm{bA}$ & & - & $37,8 \mathrm{aA}$ & \\
\hline
\end{tabular}

Médias seguidas da mesma letra minúscula na horizontal não diferem a 5\% de significância, pelo teste t.

Médias seguidas da mesma letra maiúscula na vertical não diferem a 5\% de significância, pelo teste t. 
No que se refere à interação entre os efeitos da pressão e do diâmetro dos orifícios (p x d) sobre a porcentagem de capturas simples, observa-se que somente para o maior diâmetro houve aumento na variável de resposta quando a pressão foi reduzida, e, mesmo assim, apenas do nível de $-62,7$ para $-73,1 \mathrm{kPa}$. Esse fato também pode ser explicado pelos maiores níveis de pressão efetiva no interior da câmara de vácuo com o uso do orifício de $1,5 \mathrm{~mm}$. Com exceção da maior pressão $(-56,0 \mathrm{kPa})$, a percentagem de capturas simples é estatisticamente igual entre os dois orifícios.

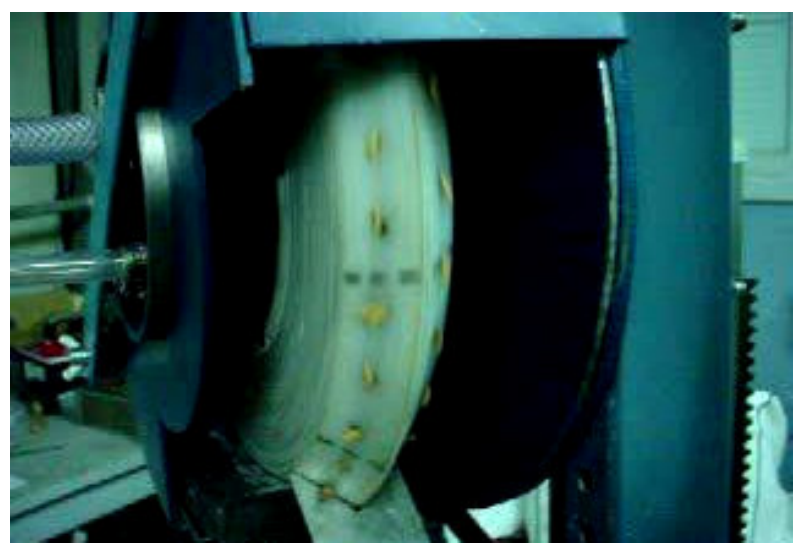

FIGURA 4. Sementes aderidas aos orifícios durante os testes de dosagem. Seeds attached to the holes during the metering tests.

De maneira geral, pode-se dizer que os melhores resultados, para o funcionamento do cilindro dosador, foram obtidos na menor velocidade tangencial e com o menor nível de pressão, independentemente do tamanho do orifício. No entanto, observou-se que, para o orifício de 1,5 mm, a percentagem de capturas simples é ligeiramente superior, chegando, em média, a 68,4\%, e também que a percentagem de capturas múltiplas é maior, chegando a $15,6 \%$ contra 4,4\% no orifício de 1,2 mm. A soma das capturas simples com as capturas múltiplas no orifício de 1,5 mm chega, portanto, a 84,0\%, gerando potencial de aumento das capturas simples pelo emprego de mecanismo exclusor de sementes eficiente. A percentagem de capturas simples e, consequentemente, a de espaçamentos aceitáveis entre sementes no sulco deveriam ser superiores a 60\%, segundo COELHO (1996), em semeadoras de precisão. Assim, verifica-se que o protótipo apresentou valores superiores àqueles esperados de dosadores de sementes graúdas.

Durante a execução do experimento, as pressões efetivas no interior da câmara de dosagem variaram, em média, de $-8,8 \mathrm{kPa}$ a $-2,7 \mathrm{kPa}$. O orifício de menor diâmetro $(1,2 \mathrm{~mm})$ necessitou de menor pressão (em média $-8,8 \mathrm{kPa}$ ) para a obtenção do maior número de dosagens simples, comparado com o maior orifício (em média $-2,7 \mathrm{kPa}$ ). Se, por um lado, isso representa vantagem para o orifício de $1,5 \mathrm{~mm}$, por outro, observou-se que é mais suscetível às variações de velocidade e de pressão em fluxo bloqueado, apresentando desempenho fraco quando a velocidade e a pressão são aumentadas. A continuidade das pesquisas desses fatores pode indicar um diâmetro intermediário, que tenha as características positivas de ambos, apresentando resultados satisfatórios na dosagem de sementes. De qualquer forma, a pressão negativa efetiva no interior da câmara deve ser mantida no maior valor possível, pois as fontes de vácuo geralmente utilizadas nas semeadoras comerciais (os ventiladores centrífugos) têm como características a alta vazão de ar e a alta pressão de vácuo, raramente atingindo níveis abaixo de $-6,0 \mathrm{kPa}$.

Os valores mais altos de capturas simples foram obtidos na menor velocidade tangencial, com o menor nível de pressão e com maior orifício; os demais experimentos foram realizados com as variáveis independentes ajustadas nesses níveis $\left(0,10 \mathrm{~m} \mathrm{~s}^{-1} ;-73,1 \mathrm{kPa}\right.$ e 1,5 mm).

\section{Regularidade de distribuição longitudinal de sementes}

A análise de variância das médias da distribuição dos tempos entre sementes não revelou diferenças estatisticamente significantes a $5 \%$ entre os tratamentos. Tanto os tempos falhos como os 
tempos aceitáveis e como os tempos múltiplos não sofreram alterações estatisticamente significativas quando a inclinação e o nível de sementes foram variados dentro dos valores considerados. As médias gerais desse experimento foram: tempos falhos 36,8\%; tempos aceitáveis $37,6 \%$, e tempos múltiplos de 25,6\%. O coeficiente de variação dos tempos aceitáveis no experimento foi de 9,9\%. Esses resultados são semelhantes aos encontrados por REIS et al. (2007), que compararam, em laboratório, o desempenho de dosadores do tipo rotor acanalado reto, rotor acanalado helicoidal e rotor dentado, na dosagem de sementes de arroz, com razão de distribuição variando entre 19 e $74 \mathrm{~kg} \mathrm{ha}^{-1}$. Os autores verificaram que, nesses três tipos de mecanismos dosadores, a percentagem de tempos aceitáveis ficou sempre abaixo de 38,2\%, podendo atingir apenas $26,0 \%$ para o rotor acanalado reto.

Observando em conjunto esses dados com aqueles obtidos no experimento anterior, vê-se que a precisão gerada na dosagem (acima de $68 \%$ de tempos aceitáveis na melhor configuração) não foi mantida após a ejeção da semente e ao seu transporte pelo tubo condutor. Isso pode dever-se a problemas de ejeção, choques das sementes no interior do tubo condutor e também ao próprio comprimento do tubo, que era propositalmente longo $(1,0 \mathrm{~m})$ como nas semeadoras de fluxo contínuo.

Embora a regularidade de distribuição longitudinal de sementes não tenha sido satisfatória, o resultado não é tão ruim, comparado com aqueles obtidos por mecanismos dosadores que apresentam o mesmo princípio de funcionamento e trabalham com sementes graúdas. MAHL et al. (2008), comparando semeadora comercial com dosador pneumático com outra de dosador de disco horizontal, na semeadura de milho, encontraram 70,3\% de espaçamento aceitáveis entre plantas para a primeira e $57,7 \%$ para a segunda. Embora esses valores sejam quase o dobro do observado no protótipo, as condições de operação foram mais favoráveis: trabalho com sementes de grandes dimensões (milho) e densidades de semeadura consideravelmente mais baixas (6 sementes por metro). Vistos sob essa perspectiva, os resultados de precisão funcional aos quais se chegou, constituem-se num começo promissor no desenvolvimento de dosadores para a semeadura de precisão de arroz.

\section{Dano mecânico das sementes}

A média geral de danos mecânicos observados na saída do tubo condutor foi de $1,8 \%$. A comparação entre o dano mecânico desse protótipo e a dano já presente no lote de sementes utilizado nos testes $(0,8 \%)$, feita através de uma análise de variância, indica que não há diferença significativa entre ambos $(\alpha=0,05)$. Então, pode se dizer que o protótipo não causa dano mecânico adicional às sementes de arroz.

\section{Testes mecânicos}

A largura total do protótipo da extremidade do eixo de acionamento até a respectiva tampa externa de fechamento é de $170 \mathrm{~mm}$. No entanto, há espaço para a redução desse valor. Acredita-se que, com a substituição do material da carcaça, a otimização das fixações das partes e das conexões de ar poderia causar redução de até $61 \mathrm{~mm}$, resultando numa largura de apenas $109 \mathrm{~mm}$.

O teste de estanqueidade transcorreu sem que se observasse aumento da pressão interna da câmara, ficando evidente a inexistência de vazamentos. O resultado positivo desse teste foi muito significativo para o desenvolvimento da concepção, pois se obteve a vedação da câmara de vácuo com um anel de diâmetro interno relativamente pequeno ( $91,4 \mathrm{~mm}$ com seção de 5,3 $\mathrm{mm}$ ), vendido em lojas especializadas.

O tempo médio da desmontagem foi de 2 min $01 \mathrm{~s}$ enquanto a montagem pode ser feita, em média, em 2 min $42 \mathrm{~s}$, perfazendo um total, para as duas operações de $4 \mathrm{~min} 43 \mathrm{~s}$.

O protótipo foi desenvolvido com apenas 32 orifícios de dosagem em cada uma das faces operativas. Considerando que os orifícios foram feitos sobre o diâmetro de $222,0 \mathrm{~mm}$ no cilindro e que a distância entre eles deve permitir o transporte das sementes com sua maior dimensão alinhada 
com a direção de deslocamento (o que corresponde ao comprimento das sementes), seria possível colocar 74 orifícios em cada face, totalizando 148. Esse número de orifícios, à velocidade tangencial de $0,10 \mathrm{~m} \mathrm{~s}^{-1}$ (correspondendo a $8,8 \mathrm{rpm}$ ), poderia dosar 21,8 sementes por segundo.

\section{CONCLUSÕES}

No que se refere ao funcionamento do protótipo na dosagem de sementes de arroz, concluiu-se que o protótipo de dosador é viável para a dosagem de precisão de sementes de arroz, sendo que a melhor percentagem de capturas simples de sementes obtida foi de $68,4 \%$. O tubo de sementes longo, com o transporte pneumático das sementes, não garantiu a precisão de deposição, pois a percentagem de espaçamentos aceitáveis ao final do tubo condutor de sementes foi de 37,6\%. Concluiu-se, também, que o protótipo não causou dano mecânico adicional às sementes de arroz e não sofreu influência significativa tanto do nível de sementes no reservatório, quanto da inclinação lateral.

Com respeito aos aspectos mecânicos e construtivos, o protótipo apresentou características desejáveis, como a dosagem com pressões efetivas no interior da câmara de dosagem relativamente elevadas (baixo vácuo), variando de $-8,8$ a $-2,7 \mathrm{kPa}$; possui largura compatível com a semeadura de culturas que necessitem pequeno espaçamento entre linhas e tempo de desmontagem e montagem inferior a 5 minutos.

\section{REFERÊNCIAS}

ABNT. ASSOCIAÇÃO BRASILEIRA DE NORMAS TÉCNICAS. Projeto de norma 04:015:06004 - Semeadora de precisão: ensaio de laboratório. São Paulo, 1994. 22 p.

BUTIERRES, E. Desempenho do mecanismo dosador pneumático a vácuo para arroz. 2003. $61 \mathrm{f}$. Tese (Doutorado em Ciência e Tecnologia de Sementes) - Faculdade de Agronomia Eliseu Maciel, Universidade Federal de Pelotas, Pelotas, 2003.

COELHO, J.L.D. Ensaio e certificação das máquinas para a semeadura. In: MIALHE, L.G. Máquinas agrícolas: ensaios e certificação. Piracicaba: Fundação de Estudos Agrários "Luiz de Queiroz", Universidade de São Paulo, 1996. cap. 11, p.551-571.

MAHL, D.; FURLANI; C.E.A.; GAMERO, C.A. Efficiency of pneumatic and horizontal perforated disk meter mechanism in corn no-tillage seeders in soil with different mobilization reports. Engenharia Agrícola, Jaboticabal, v.28, n.3, p.535-542, 2008.

MARTINS, C.F.; COSTA, R.L.; FRANZEN, T.A.; REIS, A.V. Aplicação de um filtro digital implementado em microcontrolador para sensoreamento óptico. Controle e Instrumentação, São Paulo, v.8, n.87, p.50-55, 2003.

REIS, A.V. Desenvolvimento de concepções para a dosagem e deposição de precisão para sementes miúdas. 2003. 277 f. Tese (Doutorado em Engenharia Mecânica) - Centro Tecnológico, Universidade Federal de Santa Catarina, Florianópolis, 2003.

REIS, A.V.; FORCELLINI, F.A.; RAMOS, U.A.P. Avaliação do diâmetro do orifício e da pressão de ar na dosagem pneumática de sementes de arroz. Revista Brasileira de Agrociência, Pelotas, v.12, n.2, p.191-197, 2006.

REIS, A.V.; MACHADO, A.L.T.; BISOGNIN, A. Avaliação do desempenho de três mecanismos dosadores de sementes de arroz com vistas à semeadura de precisão. Revista Brasileira de Agrociência, Pelotas, v.13, n.3, p.393-398, 2007.

REIS, A.V.; FORCELLINI, F.A. Functional analysis in the evaluation of four concepts of planters, Ciência Rural, Santa Maria, v.32, n.6, p.969-975, 2002. 